\title{
Emolehmille rehua joka toinen päivä?
}

\author{
Merja Manninen ${ }^{1)}$, Lauri Jauhiainen ${ }^{1)}$ ja Marjatta Suvitie ${ }^{2)}$ \\ 1)MTT,31600Jokioinen,merja.manninen@mtt.fi,lauri.jauhiainen@mtt.fi \\ 2) MTT, 71750 Maaninka,marjatta.suvitie@mtt.fi
}

\section{Tiivistelmä}

Emolehmien ruokinta joka toinen päivä, eläinten hyvinvoinnista tinkimättä, voi tuoda emolehmätilalle kustannussäästöä. Tämä tutkimus selvitti, voidaanko täysikasvuiset emolehmät ruokkia joka toinen päivä tuotannon heikentymättä, kun ne saavat kahden päivän rehuannoksen kerta-annoksena. Tutkimus toimi esiselvityksenä hankkeessa 'Laatulihaa tehokkaalla emolehmätuotannolla' tehdylle kokeelle, jossa eläimet ruokittiin joka kolmas päivä.

Kokeeseen otettiin 32 täysikasvuista hereford (hf)-emoa. Talven emot olivat kylmäpihaton neljässä karsinassa, jossa niillä oli mahdollisuus syödä samanaikaisesti. Emojen rehuna oli heinä. Eläimet ruokittiin lypsylehmien energiasuositusten mukaan. Rehuannosta nostettiin 60 pv ennen poikimista ja poikimisen jälkeen vastaamaan 10 kilon maitotuotosta. Emot ruokittiin joka päivä (K1) tai joka toinen päivä (K2). K2-emot saivat kahden päivän rehuannoksen kerta-annoksena. Rehun sulavuus määritettiin emoilla kokeen aikana kahdesti. Ennen vieroitusta vasikat eivät saaneet väkirehua laitumella. Emot ja vasikat punnittiin ja emot kuntoluokitettiin säännöllisesti. Poikimiset valvottiin ja arvosteltiin. Emot vasikoineen ja astutussonni laidunsivat yhtenä ryhmänä koko kesän. Laidunpinta-ala oli alkukesällä 0,58 ja loppukesällä 0,71 ha/emo-vasikka -pari.

Ajanjakso kokeen alusta poikimiseen kesti keskimäärin 151, poikimisesta laitumelle 58 ja laidunkausi 113 päivää. Yksi K1-emo poistettiin kokeesta vasikan kuoleman johdosta, muiden emojen ja vasikoiden terveys oli hyvä. Heinän D-arvo oli $61,1 \%$ ja se sisälsi raakavalkuaista 106, ND-kuitua 694 ja OIV:sta 79 g/kg KA. K2-emot söivät heinää niukasti K1-emoja enemmän. Heinän orgaanisen aineen, raakavalkuaisen ja ND-kuidun sulavuus oli hieman huonompi K2-emoilla toisella keruujaksolla. Ruokinnan vaikutus eläinten elopainoon, kuntoon tai niissä tapahtuneisiin muutoksiin oli yhdenmukainen molemmilla käsittelyillä. Emojen hyvä kunto kokeen alussa ja lypsylehmien ruokintasuositusten mukainen ruokinta lienevät vaikuttaneet siihen, että käsittelyiden välille ei muodostunut eroja. Poikimiskausi oli 8.3.-23.4.2003. Poikimiset olivat helppoja lukuun ottamatta yhtä K2-emoa, jonka vasikka oli takaperin. Emän ruokinta ei vaikuttanut vasikan kehitykseen. Ennen laidunkautta vasikoiden kasvu oli keskimäärin 1063 g/pv. Kaikki laidunkauden aloittaneet 31 emoa tiinehtyivät keskimäärin 77 pv poikimisesta.

K2-emot tottuivat nopeasti ruokintakäytäntöön. Laitumen mitoitus oli riittävä koko kesän ajan. Hyväkuntoiset, täysikasvuiset emolehmät voidaan ruokkia joka toinen päivä, kun ne silloin saavat kahden päivän rehuannoksen kerta-annoksena. Puhdasta vettä tulee olla tarjolla ja eläimillä mahdollisuus syödä yhtä aikaa ruokintapöydässä. Hyvästä hoidosta ja tarkkailusta tulee huolehtia päivittäin. Rehujen rehuarvo tulee tietää suunniteltaessa sisäruokintakauden ruokintastrategiaa. Tässä kokeessa mitatut muuttujat selittävät kuitenkin vain osittain ruokintakertojen harventamisesta aiheutuvia muutoksia eläimessä.

Asiasanat: emolehmä, frekvenssi, naudanlihantuotanto, ruokinta 


\section{Johdanto}

Emolehmätuotannon lisääminen ja tehostaminen on merkittävässä asemassa lisättäessä kotimaista naudanlihantuotantoa (Anon. 2002). Ensimmäistä ja toista kertaa poikivilla risteytysemoilla tehty tutkimus (Manninen ja Taponen 2004) osoitti, että hyväkuntoisilla emoilla päivittäisessä ruokintatarkkuudessa voi olla suuriakin vaihteluita tuotannon siitä heikentymättä, kun tietyllä aikavälillä eläimet saavat sopivasti energiaa ja valkuaista. Ruokintatarkkuutta enemmän emolehmätilan töiden järjestelyyn voisi tulla helpotusta, jos täysikasvuiset, hyväkuntoiset emot voitaisiin eläinten hyvinvoinnista tinkimättä ruokkia joka toinen päivä tai jopa harvemmin. Tällöin työhuippuina, mm. poikimiskaudella, päivittäisestä ruokintatyöstä vapautuva aika voitaisiin kohdentaa poikimisten seurantaan, syntyneiden vasikoiden merkintään ja tarkkailuun tai muuhun kiireelliseen työhön. Harvennettu ruokintastrategia ei kuitenkaan koskaan poista eläinten päivittäisen huolellisen tarkkailun ja hoidon merkitystä. Puhtaan juomaveden saanti tulee aina varmistaa. Ruokintakertojen tuotantovaikutuksia on selvitetty lypsylehmillä runsaasti (mm. Gill ja Castle 1983, Robinson ja McNiven 1994, Yun ja Han 1989). Silloin kyseessä on yleensä väkirehun annostuskertojen lisääminen. Emolehmille päivittäisen rehuannoksen jakaminen useammassa erässä ei liene perusteltua taloudellisesti eikä fysiologisesti, vaan niiden kohdalla käytännön merkitystä on rehujen annostuskertojen vähentämisellä $(7 \times$ viikossa tai $3-4 \times$ viikossa tai harvemmin) energiansaannin pysyessä vakiona tietyllä aikavälillä. Tämä tutkimus selvitti, voidaanko täysikasvuiset emolehmät ruokkia joka toinen päivä tuotannon heikentymättä, kun ne saavat kahden päivän rehuannoksen kertaannoksena. Tutkimus toimi esiselvityksenä hankkeessa 'Laatulihaa tehokkaalla emolehmätuotannolla' tehdylle emojen sisäruokintakauden kokeelle, jossa eläimet ruokittiin joka kolmas päivä.

\section{Aineisto ja menetelmät}

\section{Eläinaines, tuotanto-olosuhteet, rehut ja ruokinta}

Kokeeseen otettiin 32 hereford (hf)-emoa, jotka olivat syntyneet vuonna 1994 (10), 1996 (8), 1997 (4), 1998 (5) ja 1999 (5). Emot olivat kantavia hf-sonneille Innilän Leevi (20), Koskis Noak (8) ja Karjasuon Paukku (4). Koe alkoi 30.10.2002, laidunkausi 27.5.2003 ja koe päättyi 17.9.2003. Talven emot olivat eristämättömän pihaton neljässä samankokoisessa karsinassa, 8 emoa/karsina. Eläimillä oli mahdollisuus syödä samanaikaisesti ja niillä oli karsinakohtainen jaloittelumahdollisuus ulkotarhassa.

Emojen rehuna oli heinä, jonka energia-pitoisuus ennakkonäytteen perusteella oli 0,75 RY/kg KA. Eläimet ruokittiin lypsylehmien energiasuositusten (Tuori ym. 2002) mukaan. Rehuannosta nostettiin 60 päivää ennen poikimista ja poikimisen jälkeen vastaamaan 10 kilon maitotuotosta. Emojen elopaino kokeen alussa oli keskimäärin 745 kiloa ja kuntoluokka 3,4. Päivittäistä rehuannosta määritettäessä laskelman perusteeksi otettiin 700 kilon elopaino, koska emojen kunto oli hyvä. Emot ruokittiin joka päivä (K1) tai joka toinen päivä (K2) siten, että viime mainitussa ne saivat kahden päivän rehuannoksen kerta-annoksena. Eläimiä ei kytketty pöytään syönnin ajaksi. Tarvittaessa emojen ulottumattomissa olevaa heinää työnnettiin niiden eteen. Eläimet saivat sisäruokintakaudella P-kivennäistä (Fosfori Hertta-Minera Muro; Ca 105, P 116, Na 70 ja Mg 75 g/kg), joka vaihdettiin ennen laidunkautta Mg-kivennäiseen (Viher Hertta-Minera Muro; Ca 160, P 64, Na 90 ja Mg 80 g/kg). Vitamiinia (Mestarin ADE-vitamiini, valmistuttaja K-maatalous; A $2000000 \mathrm{KY} / \mathrm{kg}, \mathrm{D}_{3} 200000 \mathrm{KY} / \mathrm{kg}$, E 2 $000 \mathrm{mg} / \mathrm{kg}$, Niasiini $2000 \mathrm{mg} / \mathrm{kg}, B_{12} 1 \mathrm{mg} / \mathrm{kg}$, Natriumseleniitti 22,2 mg/kg vastaten Se $10 \mathrm{mg} / \mathrm{kg}$ ) annettiin ohjeen mukaan. Heinästä analysoitiin KA, tuhka, raakavalkuainen, ND-kuitu (Van Soest ym. 1991) ja orgaanisen aineen in vitro-sellulaasisulavuus (Friedel 1990). Rehun sulavuus määritettiin emoilla kokeen aikana kahdesti (13.-15.1. ja 24.-26.2) käyttäen merkkiaineena happoon liukenematonta tuhkaa (European Commission 1971). Ennen vieroitusta vasikat eivät saaneet väkirehua laitumella.

\section{Eläinten punnitukset, kuntoluokitukset ja poikimisten seuranta}

Emot punnittiin kokeen alkaessa, 60 päivää ennen poikimista, ennen poikimista (1-7 pv) ja poikimisen jälkeen (< 48 h poikimisesta), laitumelle laskettaessa ja kokeen päättyessä kahtena peräkkäisenä päivänä. Emot kuntoluokitettiin (Lowman ym. 1976) punnitusten yhteydessä, poikimisen yhteydessä kuitenkin vain kerran. Vasikat punnittiin välittömästi syntymän jälkeen, 14, 50 ja 100 päivän iässä, laitumelle laskettaessa ja kokeen päättyessä. Poikimisen arvostelu tapahtui asteikolla 1-4 ja emon suhtautuminen vasikkaan merkittiin: hyvä huolenpito, välinpitämätön ja vihainen. Ensimmäinen imeminen tallennettiin merkinnällä omatoimisesti tai auttaen. 


\section{Laiduntaminen}

Laidun oli kolmannen vuoden nurmi, joka jaettiin kahdeksaan syöttölohkoon. Neljältä lohkolta tehtiin kuiva heinä, jonka jälkeen ne otettiin laidunnukseen. Maalajina oli multava karkea hieta. Koko laidunala, 22,13 ha, lannoitettiin keväällä Pellon Y6-lannoitteella 315 kg/ha, josta 54 kg N/ha ja myöhemmin Suomen salpietarilla $270 \mathrm{~kg} / \mathrm{ha}$, josta $70 \mathrm{~kg}$ N/ha. Kaksi lohkoa sai edellä mainittujen lannoitusten lisäksi Pellon NK-lannoitetta 250 kg/ha, josta 50 kg N/ha. Kahdella lohkolla Suomen salpietari puolestaan korvattiin Pellon NK-lannoitteella, josta $50 \mathrm{~kg}$ N/ha. Lannoitukset ja puhdistusniitot tehtiin välittömästi laidunnusten jälkeen. Emot vasikoineen laidunsivat yhtenä ryhmänä koko kesän astutussonnina Innilän Leevi, joka oli laumassa 6.6.-2.9.2003. Tiineystarkastukset tehtiin 15.8. ja 2.10.2003. Laidunpinta-ala oli alkukesällä 0,58 ja loppukesällä 0,71 ha/emo-vasikka -pari. Laidunkivennäisenä oli Viher Hertta-Minera Muro.

\section{Tilastollinen käsittely}

Tilastolliset analyysit tehtiin SAS-ohjelmiston GLM-proseduurilla (SAS 1999). Emojen elopainoja ja kuntoja tarkasteltaessa tilastollinen malli oli seuraava: $y_{i j}=\mu+O_{i}+p_{j}\left(O_{i}\right)+\varepsilon_{i j}$, missä y=vastemuuttuja, $\mu=$ keskiarvo, $\mathrm{O}=$ käsittely, $\mathrm{p}_{\mathrm{j}}=$ karsinakohtainen satunnaistekijä ja $\varepsilon_{\mathrm{ij}}=$ virhetermi. Koeyksikkönä tässä tilastollisessa käsittelyssä oli karsina, jolloin käsittely -tekijän virheterminä toimi karsinoiden välinen vaihtelu. Vasikka-aineistoa käsiteltäessä huomioitiin vasikan syntymäpäivä mallissa lineaarisena regressiotekijänä. Näin malli poisti syntymäajankohdan vaikutuksen vasikoiden välisestä vaihtelusta. Vasikka-aineistossa mallissa oli myös vasikan sukupuoli ja sukupuoli*käsittely -yhdysvaikutus, joita testattaessa virheterminä käytettiin normaalijakautunutta jäännösvirhettä.

\section{Tulokset ja tulosten tarkastelu}

Ajanjakso kokeen alusta poikimiseen kesti keskimäärin 151 (SD 11,8) päivää ja poikimisesta laitumelle 58 (SD 11,9) päivää. Laidunkauden pituus oli 113 päivää. Yksi K1-emo poistettiin kokeesta 20.4. vasikan kuoleman johdosta (vasikka syntyi 6.4., EELA:n lausunto: yleistulehdus, niveltulehdus, keuhkotulehdus). Muilta osin emojen ja vasikoiden terveys oli hyvä eikä kliinisiä oireita havaittu. Heinän KA-pitoisuus oli keskimäärin $869 \mathrm{~g} / \mathrm{kg}$. In vitro/in vivo -sulavuuksiin perustuvat D-arvot olivat vastaavasti 61,0/61,2 \%. Raakavalkuaista heinä sisälsi 106, ND-kuitua 694 ja OIV:sta 79 g/kg KA. Heinän laskennallinen energia-arvo oli 0,79 RY/kg KA. K2-emot söivät heinää talvikaudella niukasti K1emoja enemmän, minkä johdosta myös niiden energian saanti muodostui marginaalisesti suuremmaksi $(\mathrm{P}<0,05$, Taulukko 1). Heinän orgaanisen aineen, raakavalkuaisen ja ND-kuidun sulavuus oli suuntaa antavasti huonompi K2-emoilla toisella keruujaksolla (Taulukko 1). K1-emoilla kaikkien muuttujien sulavuus parani siirryttäessä ensimmäiseltä toiselle keruujaksolle, kun vaikutus K2-emoilla oli päinvastainen.

Ruokinnan vaikutukset eläinten elopainoon, kuntoon tai niissä tapahtuneisiin muutoksiin olivat yhdenmukaiset molemmilla käsittelyillä (Taulukko 2). Täysikasvuisten emojen hyvä kunto kokeen alussa, lypsylehmien ruokintasuositusten mukainen ruokinta ja heinän ennakkonäytteen arvoihin perustuva ruokinta lienevät vaikuttaneet siihen, että käsittelyiden välille ei muodostunut eroja. Myös ryhmät olivat tasaiset ja kaikilla emoilla oli mahdollisuus syödä samanaikaisesti.

Poikimiskausi ajoittui ajalle 8.3.-23.4.2003 keskimääräisen poikimispäivän ollessa 30.3.2003 (Taulukko 3). Maaliskuussa syntyi 18 vasikkaa ja huhtikuussa 14 vasikkaa. Poikimiset olivat helppoja lukuun ottamatta yhtä K2-emoa, jonka vasikka oli takaperin. Emot suhtautuivat vasikkaansa hyvin lukuun ottamatta yhtä K1-emoa, joka oli vihainen muille vasikoille. Ensimmäinen imeminen tapahtui omatoimisesti, viittä vasikkaa avustettiin hieman. Emän ruokinta ei vaikuttanut vasikan kehitykseen. Syntymäpainossa oli lievä yhdysvaikutus, sillä K2-lehmävasikat olivat keskimäärin 3,4 kiloa painavampia kuin K2-sonnivasikat tilanteen ollessa päinvastoin K1-vasikoilla. Ennen laidunkautta vasikoiden päiväkasvu oli keskimäärin 1063 g. Laitumella ja koko kokeen ajalle laskettuna sonnivasikat kasvoivat lehmävasikoita paremmin ( $\mathrm{P}<0,05,1389$ vs. 1232 ja 1294 vs. 1158 g/pv). Kokeen päättyessä vasikat olivat keskimäärin 5,5 kuukauden ikäisiä. Sonnivasikat painoivat tuolloin keskimäärin 263 ja lehmävasikat 239 kiloa $(\mathrm{P}<0,05)$. Kaikki laidunkauden aloittaneet 31 emoa tiinehtyivät keskimäärin 77 päivää poikimisesta. 
Taulukko 1. Syönti ja energian saanti (in vitro / in vivo) sekä heinän orgaanisen aineen (OA), raakavalkuaisen (RV) ja ND-kuidun sulavuus ja sulavuuden muutokset.

\begin{tabular}{|c|c|c|c|c|}
\hline Ruokinta & $\mathrm{K} 1$ & $\mathrm{~K} 2$ & SEM $^{1}$ & Merkitsevyys $^{2}$ \\
\hline Ryhmiä & 2 & 2 & & \\
\hline \multicolumn{5}{|l|}{ Heinästä, } \\
\hline $\mathrm{KA}, \mathrm{kg}$ & 11,0 & 11,1 & 0,02 & $*$ \\
\hline $\mathrm{RV}, \mathrm{g}$ & 1160 & 1176 & 2,4 & $*$ \\
\hline NDF, g & 7566 & 7672 & 15,7 & $*$ \\
\hline $\mathrm{RY}$ & 8,7 / 8,7 & 8,8 / 8,8 & $0,02 / 0,02$ & $* / *$ \\
\hline OIV, g & 867 / 869 & 879 / 881 & $1,85 / 1,85$ & $* / *$ \\
\hline \multicolumn{5}{|l|}{ Sulavuus } \\
\hline OA, 1. keruu & 0,641 & 0,639 & 0,0263 & \\
\hline RV, 1. keruu & 0,583 & 0,572 & 0,0358 & \\
\hline NDF, 1. keruu & 0,677 & 0,674 & 0,0253 & \\
\hline OA, 2. keruu & 0,705 & 0,586 & 0,0278 & o \\
\hline RV, 2. keruu & 0,605 & 0,447 & 0,0341 & 0 \\
\hline NDF, 2. keruu & 0,730 & 0,622 & 0,0228 & o \\
\hline \multicolumn{5}{|l|}{ Muutos $1 . \rightarrow 2$} \\
\hline $\mathrm{OA}$ & 0,063 & $-0,053$ & 0,0424 & \\
\hline RV & 0,021 & $-0,125$ & 0,0622 & \\
\hline NDF & 0,052 & $-0,052$ & 0,0359 & \\
\hline
\end{tabular}

${ }^{1}$ Keskiarvon keskivirhe.

2 о $\mathrm{P}<0,10$; * $\mathrm{P}<0,05$; ** $\mathrm{P}<0,01$; *** $\mathrm{P}<0,001$.

Taulukko 2. Emojen elopaino, kunto ja niissä tapahtuneet muutokset.

\begin{tabular}{|c|c|c|c|c|}
\hline Ruokinta & K1 & K2 & SEM $^{1}$ & Merkitsevyys $^{2}$ \\
\hline Eläinten lukumäärä & $16^{3}$ & 16 & & \\
\hline Vuoden alusta poikimiseen, pv & 89 & 89 & 1,0 & \\
\hline \multicolumn{5}{|l|}{ Elopaino, $\mathrm{kg}$} \\
\hline Alussa & 745 & 746 & 1,2 & \\
\hline 60 pv ennen poikimista & 796 & 795 & 3,8 & \\
\hline Ennen poikimista & 842 & 842 & 3,3 & \\
\hline Poikimisen jälkeen & 784 & 783 & 4,2 & \\
\hline Laidunkauden alkaessa & 757 & 761 & $13,6-14,1$ & \\
\hline Kokeen päättyessä & 807 & 810 & $6,0-6,2$ & \\
\hline \multicolumn{5}{|l|}{ Elopainon muutos, $g / p v$} \\
\hline Sisällä & 67 & 72 & $68,2-70,6$ & \\
\hline Laitumella & 447 & 428 & $69,6-72,0$ & \\
\hline Kokeen aikana & 200 & 197 & $22,8-23,6$ & \\
\hline \multicolumn{5}{|l|}{ Kuntoluokka ${ }^{4}$} \\
\hline Alussa & 3,36 & 3,37 & 0,093 & \\
\hline $60 \mathrm{pv}$ ennen poikimista & 3,19 & 3,17 & 0,040 & \\
\hline Poikiessa & 3,20 & 3,20 & 0,017 & \\
\hline Laidunkauden alkaessa & 3,49 & 3,38 & $0,123-0,127$ & \\
\hline Kokeen päättyessä & 3,69 & 3,71 & $0,159-0,164$ & \\
\hline \multicolumn{5}{|l|}{ Kuntoluokan muutos } \\
\hline Sisällä & 0,12 & 0,01 & $0,118-0,122$ & \\
\hline Laitumella & 0,20 & 0,33 & $0,057-0,059$ & \\
\hline Kokeena aikana & 0,32 & 0,34 & $0,119-0,123$ & \\
\hline
\end{tabular}

${ }^{1}$ Keskiarvon keskivirhe.

${ }^{2}$ о $\mathrm{P}<0,10$; * $\mathrm{P}<0,05$; ** $\mathrm{P}<0,01$; *** $\mathrm{P}<0,001$.

${ }^{3}$ Yksi emo poistettu kokeesta 20.4.2003

${ }^{4}$ Kuntoluokitus: 0=erittäin laiha...5=ylilihava, arvostelu +,-,1/2. 
Taulukko 3. Vasikoiden kehitys.

\begin{tabular}{|c|c|c|c|c|c|c|c|}
\hline \multirow{2}{*}{$\begin{array}{l}\text { Ruokinta (R) } \\
\text { Sukupuoli (S) }\end{array}$} & \multicolumn{2}{|c|}{ K1 } & \multicolumn{2}{|c|}{ K2 } & \multicolumn{3}{|c|}{ Merkitsevyys $^{2}$} \\
\hline & Sonni & Lehmä & Sonni & Lehmä & $\mathrm{SEM}^{1}$ & $\mathrm{R} \quad \mathrm{S}$ & $\mathrm{R} \times \mathrm{S}$ \\
\hline Eläinten lukumäärä & $10^{3}$ & 6 & 8 & 8 & & & \\
\hline Syntymäpäivä ${ }^{4}$ & 92 & 82 & 89 & 90 & $3,9-5,0$ & & \\
\hline \multicolumn{8}{|l|}{ Elopaino, $\mathrm{kg}$} \\
\hline Syntymäpaino & 42,6 & 38,2 & 40,7 & 44,1 & $1,72-2,26$ & & 0 \\
\hline $14 \mathrm{pv}$ & 58,7 & 55,7 & 58,8 & 60,4 & $2,72-3,38$ & & \\
\hline $50 \mathrm{pv}$ & 98,5 & 87,6 & 94,7 & 95,7 & $4,55-5,66$ & & \\
\hline $100 \mathrm{pv}$ & 162 & 144 & 154 & 154 & $7,0-8,8$ & & \\
\hline Laidunkauden alkaessa & 109 & 96 & 104 & 104 & $4,9-6,1$ & & \\
\hline Kokeen päättyessä & 272 & 231 & 255 & 247 & $10,4-13,0$ & $*$ & \\
\hline \multicolumn{8}{|l|}{ Elopainon muutos, $g / p v$} \\
\hline Sisällä & 1133 & 1009 & 1078 & 1018 & $66,2-82,4$ & & \\
\hline Laitumella & 1445 & 1189 & 1333 & 1274 & $63,0-78,4$ & $*$ & \\
\hline Kokeen aikana & 1338 & 1129 & 1250 & 1187 & $54,5-67,7$ & $*$ & \\
\hline
\end{tabular}

${ }^{1}$ Keskiarvon keskivirhe.

2 o $\mathrm{P}<0,10$; * $\mathrm{P}<0,05$; ** $\mathrm{P}<0,01$; *** $\mathrm{P}<0,001$.

${ }^{3}$ Vasikka kuoli 20.4.2003.

${ }^{4} 1.1 .2003=1$.

\section{Johtopäätökset}

Emojen ruokinta joka toinen päivä ei vaikuttanut emojen kuntoon, elopainoon, vasikoiden kehitykseen tai emojen tiinehtymiseen laidunkaudella. Kaikkien eläinten terveys oli hyvä. Joka toinen päivä ruokitut emot tottuivat nopeasti ruokintakäytäntöön eikä levottomuutta esiintynyt muutaman alkupäivän jälkeen. Emojen kuntoluokkien perusteella laitumen mitoitus oli vähintäänkin riittävä koko kesän ajan. Tulosten perusteella hyväkuntoiset, täysikasvuiset emolehmät voidaan ruokkia joka toinen päivä, kun ne silloin saavat kahden päivän rehuannoksen kerta-annoksena. Puhdasta vettä tulee olla aina tarjolla ja eläimillä mahdollisuus syödä yhtä aikaa ruokintapöydässä. Hyvästä hoidosta ja tarkkailusta tulee huolehtia päivittäin. Käytettävien rehujen rehuarvo tulee tietää suunniteltaessa sisäruokintakauden ruokintastrategiaa. Tässä kokeessa mitatut muuttujat selittävät kuitenkin vain osittain ruokintakertojen harventamisesta aiheutuvia muutoksia eläimeen. Tämän kokeen jälkeen tehtiin MTT:n emolehmänavetalla samoilla emoilla koe, jossa ne ruokittiin joka kolmas päivä, toisin sanoen emot saivat kolmen päivän rehuannoksen kerta-annoksena. Kokeessa selvitettiin ruokinnan vaikutuksia emojen tuotantoon, mutta myös eläinten käyttäytymiseen, veriparametreihin, maidontuotantoon ja sen koostumukseen. Samassa yhteydessä Työtehoseura selvitti vaikutukset työajankäyttöön.

Kiitokset MTT:n emolehmänavetan EMO-tiimille kokeen huolellisesta toteutuksesta ja eläinten hyvästä hoidosta.

\section{Kirjallisuus}

Anon. 2002. Kotimaisen naudanlihantuotannon elvyttämistä selvittävä työryhmä. Loppuraportti.

Työryhmämuistio MMM 2002:2. Helsinki. 38 p.

European Commission. 1971. Commission Directive 71/250/EEC. Determination of ash which is insoluble in hydrochloric acid. Official Journal No L 155/13, 30-31 (Method B).

Friedel, K. 1990. Die Schätzung des energetischen Futterwertes von Grobfutter mit Hilfe einer

Cellulasemethode. [The estimation of the energetic feeding value of roughages by means of cellulase method]. Wissenschaftliche Zeitung Universitet Rostock, N-Reihe 39, 78-86.

Gill, M.S. \& Castle, M.E. 1983. The effects of the frequency of feeding concentrates on milk production and eating behaviour in Ayrshire dairy cows. Anim. Prod. 36: 79-85.

Lowman, B.G., Scott, N.A. \& Sommerville, S.H. 1976. Condition Scoring of Cattle.The East of Scotland College of Agriculture. Animal Production, Advisory and Development Department. Bulletin No.6. 31 p.

Manninen, M. \& Taponen, J. 2004. Influence of feeding accuracy on the performance of Aberdeen Angus $\times$ Ayrshire and Charolais $\times$ Ayrshire crossbred suckler cows and their progeny. Livest. Prod. Sci. 85: 65-79.

Robinson, P.H. \& McNiven M.A. 1994. Influence of Flame Roasting and Feeding Frequency of Barley on Performance of Dairy Cows. J. Dairy Sci. 77: 3631-3643. 
SAS. 1999. SAS/STAT User's Guide, Version 8, Cary, NC: SAS Institute Inc. 3809 p.

Tuori, M., Kaustell, K., Valaja, J., Aimonen, E., Saarisalo, E. \& Huhtanen, P. 2002. Rehutaulukot ja ruokintasuositukset. Helsinki. 99 p.

Van Soest, P.J., Robertson, J.B. \& Lewis, B.A. 1991. Methods for dietary fiber, neutral detergent fiber and nonstarch polysaccharides in relation to animal nutrition. J. Dairy Sci. 74: 3583-3597.

Yun, S.K. \& Han, J.D. 1989. Effect of feeding frequency of concentrate to milking cow in early lactation on $\mathrm{pH}$ and VFA-concentration in rumen fluid and on milk composition and milk yield. Asian-Australasian J. Anim. Sci. 2: $418-420$. 